\title{
"UMA FLOR MURCHA": A CRÔNICA BRASILEIRA ENTRE 0 JORNAL E O LIVRO
}

\section{"THE WILTED FLOWER": BRAZILIAN CHRONICLE BETWEEN THE NEWSPAPER AND THE BOOK}

\author{
Marcus Vinicius Nogueira Soares ${ }^{1}$
}

RESUMO: O presente ensaio destaca o debate, ocorrido nas décadas de 1950 e 1960 nos principais periódicos do Rio de Janeiro e São Paulo, sobre o valor literário da crônica, baseado na contraposição entre a origem jornalística do gênero e a sua entrada cada vez mais constante no mercado de livros. Depois, analisa os limites críticos desse debate que permitem pensar no estabelecimento de um lugar específico para o gênero dentro de uma historiografia que comporte a sua dimensão mais propriamente jornalística.

PALAVRAS-CHAVE: Crônica brasileira. Jornalismo. Mercado editorial. História literária.

\begin{abstract}
This paper presents the debate, which occurred in the 1950s and 1960s in the main journals of Rio de Janeiro and São Paulo, on the literary value of the chronicle, based on the contrast between the journalistic source of the genre and its entry increasingly constant in the book market. Then it analyzes the critical limits of this debate that enable possibility of setting a specific place for the genre within a historiography which presents its more properly journalistic dimension.

KEYWORDS: Brazilian Chronicle. Journalism. Book Market. Literary History.
\end{abstract}

\footnotetext{
${ }^{1}$ Professor da Universidade do Estado do Rio de Janeiro.
} 


\section{“UMA FLOR MURCHA": A CRÔNICA BRASILEIRA ENTRE O JORNAL E O LIVRO}

\section{INTRODUÇÃO}

O texto a seguir é fruto do trabalho que se encontra em curso e que consiste na tentativa de delinear uma história da crônica brasileira dos séculos XIX e XX. Como boa parte das reflexões que norteiam a minha pesquisa surgiu da leitura do debate da crítica literária em torno do gênero no período de seu grande boom editorial no Brasil, entre as décadas de 1950 e 1970, proponho destacar certas posições assumidas pelos críticos no interior do debate, com o intuito de examiná-las mais de perto. De imediato, adianto que, por economia de espaço, apresento apenas duas questões: de um lado, a que se refere ao fenômeno que motivou o debate, ou seja, o aumento exponencial da publicação de livros de crônica; de outro, pretendo abordar o modo como a crítica reage ao fenômeno, problematizando a relação entre gêneros e meios de difusão (jornal, livro etc.) que, no caso da crônica, envolve a afirmação ou não de sua literariedade.

Passo, então, ao debate.

\section{UMA ENXURRADA DE LIVROS DE CRÔNICAS}

Em artigo publicado em $O$ Estado de S. Paulo de 20 de outubro de 1957, Temístocles Linhares, logo na abertura, chama a atenção para um crescente fenômeno editorial: "Continuam a aparecer mais livros de crônicas" (LINHARES, 1957, p.4). A constatação vem à baila diante da necessidade de se resenhar três coletâneas recém-lançadas naquele ano, todas pela editora José Olympio: Fala, amendoeira, de Carlos Drummond de Andrade, A cidade e a roça, de Rubem Braga, e Páginas vadias, de Leo Vaz. No diagnóstico do crítico paranaense, por mais que se tratasse de grandes escritores e de crônicas bem realizadas, tal nível de excelência não seria capaz de superar os limites do gênero que, ao contrário, se tornariam cada vez mais estreitos à medida que a crônica abandona o dinamismo veloz das páginas dos jornais, onde ainda se percebe certo desprendimento prazeroso em sua leitura, para se inserir no "aristocratismo que a composição do livro de qualquer modo encerra" (LINHARES, 1957, p.4). Além disso, Linhares ainda especula, mais especificamente 
sobre o livro de Drummond, se o leitor mais exigente não se perguntaria, ao reconhecer prosa tão bem elaborada em gênero insuficiente, se o autor não estaria "gastando cera com tão mau defunto" (LINHARES, 1957, p.4).

O trabalho quase diário de crítica literária jornalística levou Linhares a se deparar novamente com livros de crônicas. Em 16 de fevereiro de 1963, ele resenha os lançamentos de Vivaldo Coaracy, Stanislaw Ponte Preta e mais um volume de Drummond. De novo, a questão é colocada em termos paradoxais: apesar de objeto durável, o livro não concede perenidade às crônicas, visto que acaba acentuando, contraditoriamente, a "efemeridade" e a "perecibilidade" do gênero, tornando-o, assim, mais superficial do que no seu suporte de origem, o jornal:

\begin{abstract}
Arte menor, a crônica não suportava o livro, virando coisa muito rala, com o tempo sempre a espioná-la, a devorá-la depressa ou a sepultar sem piedade o que já nascia para morrer, vivendo apenas um dia da semana, um domingo ou um sábado. (LINHARES, 1963, p.4)
\end{abstract}

Ora, se apesar de enfraquecida no livro, a crônica ainda faz sucesso, é porque, segundo o crítico, "o gosto do leitor brasileiro se contenta com pouco" (LINHARES, 1963, p.4). Daí, a contundente hipótese apresentada por Linhares, baseada em argumento de índole intelectual, de que a crônica seria eminentemente brasileira:

[A crônica] condiz bem com a nossa psicologia, com o nosso espírito crítico superficial, com o nosso lirismo também superficial, já não falando da instabilidade, outro aspecto a ser considerado no caso, uma vez que é de nosso maior agrado saber um pouco de tudo, borboletear sobre os assuntos, do que, por exemplo, saber a fundo uma coisa só. (LINHARES, 1963, p.4)

Em outras palavras, a crônica seria a forma que melhor expressa a precariedade do sistema intelectual brasileiro pouco afeito à reflexão crítica e ao estudo aprofundado. De acordo com Linhares, isso explica porque, em outras literaturas, como a inglesa, francesa ou norte-americana, a crônica não proliferou em livro.

Cumpre salientar que a posição de Linhares não é compartilhada por toda a imprensa paulistana e nem mesmo por todos colaboradores do jornal onde ele escreve. Companheiros de redação, como Antonio Candido, Luís Martins e Edgard Cavalheiro, manifestam-se favoravelmente ao gênero. O último, inclusive, ao comentar o mesmo Fala, amendoeira, de Drummond, não deixa de constatar o mencionado fenômeno, "quem quer que acompanhe o movimento editorial brasileiro, terá notado, nestes últimos tempos, um afluxo incomum de livros de crônica" (CAVALHEIRO, 1957, p.4), sem, contudo, desqualificar o gênero, muito menos tomando-o como sintoma de deficiência intelectual.

$\mathrm{Na}$ verdade, é na imprensa carioca que o debate se acentua e ganha status de polêmica.

Em depoimento publicado por Esdras do Nascimento na Tribuna da Imprensa de 24 de julho de 1963, o cronista do Correio da Manhã, Carlos Heitor Cony, afirma que a crônica não é gênero mas "negócio literário" (NASCIMENTO, 1963, p.9) bastante lucrativo e que por isso ele pretendia lançar uma reunião de seus escritos jornalísticos em livro, o que ocorre com a publicação Da arte de falar mal, ainda no mês de julho. Apesar do ofício exercido quase diariamente, Cony lembra que gostaria de ser julgado pela sua obra literária, pelos seus romances, avaliação que já se encontrava em curso pois, apesar da carreira curta - em 1963, ele já tinha publicado cinco romances, sendo o primeiro, $O$ ventre, em 1958 -, ele vencera duas vezes o prestigiado prêmio "Manuel Antônio de Almeida" e todos os seus livros vinham sendo impressos por um editora de ponta, a Civilização Brasileira, inclusive o mencionado volume de crônicas. Para Cony, a atividade de cronista não passava de distração que ele 
desempenhava "por motivos pessoais, absolutamente extraliterários" (NASCIMENTO, 1963, p.9).

José Carlos Oliveira, cronista do Caderno B do Jornal do Brasil, prontamente se manifesta contra o autor de Tijolo de Segurança. Em texto de 26 de julho de 1963, intitulado "Declaração de honestidade", publicado em sua coluna diária "O homem e a fábula", Oliveira ressalta a contradição de Cony que parece não se decidir entre ser um autêntico romancista ou um cronista embusteiro: “(...) mas a verdade é que há apenas escritores. Há escritores que eventualmente escrevem crônicas e há escritores que, quando fingem estar escrevendo uma crônica, estão em realidade fazendo um negócio literário" (OLIVEIRA, 1963, p.1). Como se não bastasse, Oliveira encontra-se dias depois defendendo a sua própria obra, no caso, reagindo à crítica de Tite de Lemos à sua recém-lançada coletânea de crônicas Os olhos dourados do ódio. Em sua resenha, o poeta carioca chega a afirmar, ecoando Cony, que "escrever uma crônica é (...) enfim o meio mais seguro de ser-se escapista em literatura" (LEMOS, 1963, p.89).

Por sua vez, Esdras do Nascimento volta ao assunto, ainda em julho, na mesma Tribuna da Imprensa, em texto intitulado "Cony com razão: crônica é negócio". Motivado por mais um novo livro de crônicas, Quadrante 2, cujo primeiro volume havia sido "um dos maiores feitos editoriais do ano passado" (NASCIMENTO, 1963, p. 9), Nascimento remete ao artigo de José Carlos Oliveira, contudo para ratificar as declarações de Cony e alertar para o "perigo de esterilização literária" decorrente da "deformação profissional" (NASCIMENTO, 1963, p.1) de escritores que abandonam a realização de obras literariamente válidas para se dedicarem única e exclusivamente à produção de crônicas.

Por fim, em artigo estampado na seção "Literatura" do Caderno B do Jornal do Brasil de 7 de agosto de 1963, "A crônica é o limite", Francisco de Assis Almeida Brasil escreve, ecoando Linhares e Nascimento, contra a "enxurrada de livros de crônica publicada ultimamente", segundo ele, um "mau sinal para literatura brasileira", já que, por um lado, converte o escritor de talento, entregue ao percurso fácil e lucrativo, em "cronista leviano, superficial e romântico", e, por outro, explicita certa atividade editorial perniciosa, na qual se vende "crônica jornalística como literatura" (BRASIL, 1963, p.2). Para o crítico, a conjuntura mostra-se ainda mais problemática, pois editoras estavam sendo fundadas com esse intuito, estimulando o meio literário a considerar qualquer idiossincrasia autoral como assunto de crônica. O resultado, segundo Assis Brasil, não poderia ser outro se não a valorização de uma verve poética que "não passa de um lirismo choramingas completamente ultrapassado", transformando o cronista em um "beletrista moderno" (BRASIL, 1963, p.2) completamente anacrônico, uma vez que inadaptado às práticas literárias e jornalísticas de seu tempo.

Tudo leva a crer que Assis Brasil se refira à Editora do Autor, empresa responsável desde 1960 pela publicação de volumes de crônicas de autores já bastante reconhecidos em outros gêneros literários como Manuel Bandeira, Clarice Lispector, Paulo Mendes Campos, Carlos Drummond de Andrade, Rachel de Queirós, além de livros de seus próprios fundadores, Rubem Braga e Fernando Sabino - o outro sócio seria Walter Acosta, autor de livros jurídicos.

\section{A CRÔNICA NO LIVRO: UMA FLOR MURCHA}

Feito esse breve apanhado de alguns posicionamentos críticos do debate, gostaria, agora, de retomar as duas questões mencionadas logo na abertura do presente ensaio. A primeira, como se viu, diz respeito à motivação do debate: o fenômeno do aumento expressivo de livros de crônica. Fazendo um rápido retrospecto até o século XIX, é possível dizer que a prática de editar crônicas no Brasil só começa a ganhar terreno na década de 1870: a iniciativa de José Maria Vaz Pinto Coelho de organizar, em 1874, o volume com a série "Ao 
correr da pena", de José de Alencar, vinte anos depois de ter saído no Correio Mercantil, a coletânea Folhetins, de França Junior, de 1878, elaborada a partir de material impresso na Gazeta de Notícias, e o lançamento de Fantasias, de Alfredo Bastos, em 1879, com uma seleção de seus textos do Jornal do Commércio, podem ser tomados como sintoma inicial dessa tendência. Entretanto, apesar de o crescimento do fenômeno ser cada vez mais perceptível nas décadas seguintes (Olavo Bilac, Coelho Netto, João do Rio, dentre outros, vão também estampar as suas crônicas em livro), é só entre as décadas de 1920 e 1930 que ele ganha impulso.

Em parte, isso pode ser creditado às grandes empresas de comunicação que, ao expandirem os seus domínios pelo território nacional, criando uma vasta rede de difusão através da articulação entre os principais veículos de massa da época (jornal, revista e rádio), acabam por disseminar a crônica. Criado em 1924, no Rio de Janeiro, com a aquisição do periódico $O$ Jornal por Assis Chateaubriand, o grupo Diários Associados é o mais importante conglomerado do período. É nele que Rubem Braga aparece, em 1932, para o público mais amplo, escrevendo para os jornais mineiros Diário da Tarde e Estado de Minas, ambos de propriedade do grupo. Esse vínculo não só vai permitir que Braga trabalhe em algumas das redações da empresa espalhadas pelo país, em cidades como São Paulo, Rio de Janeiro e Recife, como também permite a circulação de seus textos nos periódicos das localidades nas quais o autor ainda não se encontrava presente - por exemplo, quando ele chega à capital pernambucana em 1935, as suas crônicas já eram publicadas pelo Diário de Pernambuco, folha que pertencia aos Diários Associados.

Além disso, a visibilidade alcançada por Rubem Braga vai se traduzir em boa aceitação crítica de sua obra mesmo sem ter publicado sequer um livro. Ao final do ano de 1934, o autor capixaba aparece na lista de votados do concurso "Príncipe dos Prosadores", organizado por outra folha da empresa de Chateaubriand, o Diário da Noite, com o intuito de homenagear o romancista Coelho Netto, recém-falecido e detentor do título. Na lista, figuravam ainda, dentre outros nomes consagrados, Humberto de Campos, que liderava amplamente a votação quando morre em 5 de dezembro, o eleito Ronald de Carvalho, Marques Rebelo, Monteiro Lobato e José Lins do Rego - a eleição era direta e não havia prévia indicação de candidaturas por parte do jornal. Para que se tenha ideia da amplitude do processo, no exemplar de 3 de dezembro de 1934, os organizadores apresentam a relação de alguns participantes do eleitorado que vai de Carlos Drummond de Andrade (o primeiro a votar em Braga) a Vivaldo Coaracy, passando por Gilberto Freyre e Augusto Meyer, em um total de oitenta e nove nomes. O resultado final da eleição é divulgado em 16 de janeiro de 1935, em listagem de trinta e dois escritores na qual os grandes destaques são as ausências, considerando o prestígio que esses autores têm hoje: Jorge Amado, Mário de Andrade, Graciliano Ramos e Érico Veríssimo.

Assim, quando Rubem Braga reúne, apenas quatro anos após o seu início em Minas, parte de sua produção no livro de estreia $O$ conde e o passarinho de 1936, pela editora José Olympio, ele já era um escritor reconhecido nacionalmente através única e exclusivamente dos veículos jornalísticos.

O interesse de uma editora que, à época, publicava os principais autores brasileiros em atividade, é revelador de uma perspectiva editorial que não via incongruência entre o formato da crônica e a materialidade do livro. Além disso, tratava-se de apostar na boa resposta comercial, considerando a experiência de livros de crônicas como o do prestigiadíssimo Humberto de Campos, Os párias, que, lançado pela mesma José Olympio, em 1933, alcançava, no ano seguinte, a sexta edição, feito que contribuiu para o rápido crescimento da editora, motivando a empresa a continuar investindo no gênero nas décadas seguintes, como se percebe nas obras resenhadas por Linhares nos artigos aqui citados de 1957 e 1963: dos seis livros mencionados pelo crítico, apenas dois não pertencem ao catálogo 
da José Olympio, Primo Altamirando e elas, de Stanislaw Ponte Preta, e A bolsa e a vida, de Drummond, ambos da Editora do Autor.

Em suma, o fenômeno não é novo, embora se intensifique nas décadas de 1950 e 1960.

Apesar da boa recepção de público e de crítica - o livro de Rubem Braga não fez mais do que endossar a repercussão favorável que o gênero já possuía nas páginas dos jornais da época -, a crônica não deixa de provocar divergência. Em 1930, Alceu de Amoroso Lima, mais conhecido pelo pseudônimo Tristão de Ataíde, ao resenhar a recém-lançada coletânea de crônicas de Henrique Pongetti, Câmera lenta, aponta para a inadequação entre o gênero e o livro:

Nas páginas de um livro uma crônica (...) dá sempre a impressão de uma flor murcha, dessas que antigamente se guardavam nos livros, e que lembram apenas, melancolicamente, o frescor da vida que possuíram. Uma crônica num livro é como passarinho afogado. Tira a respiração e não interessa. (LIMA, 1933, p.5)

Comparando com o que foi dito pelos envolvidos no debate trinta anos depois, percebe-se o círculo vicioso no qual se encontra a crítica sobre a crônica. Diante desse imobilismo, gostaria de formular a seguinte questão: não estaria o livro apenas atestando a sobrevivência de um gênero da qual o boom editorial da segunda metade do século XX seria mero sintoma? O que não se manifesta no texto de Amoroso Lima, talvez porque ele não estivesse acossado pela "enxurrada de livros de crônicas", é o que me parece nortear a perspectiva posterior, ou seja, a ideia da crônica como "negócio literário". Vale assinalar que a expressão diz respeito não só ao produto que se está negociando, à sua qualidade intrínseca, mas também à suposta má-fé dos editores, afinal, nas palavras de Assis Brasil, as editoras vendiam "crônica jornalística como literatura". É claro que, para esses críticos, não haveria problema que crônicas fossem vendidas nos jornais, mas, no livro, seria confundir instâncias discursivas hierarquicamente bem distintas. Para tratar desse aspecto que corresponde à segunda questão inicialmente proposta sobre a relação entre gêneros discursivos e meios de difusão, creio que o melhor seria trilhar caminho inverso, atentando agora para a posição crítica favorável à crônica, uma vez que entende que ela pode ser literária.

\section{A CRÔNICA NO LIVRO: O PODER DE TRANSCENDÊNCIA LITERÁRIA}

Considerando as dimensões do presente ensaio, detenho-me em um único artigo de Eduardo Portella, lembrando sempre que as reflexões aqui desenvolvidas podem ser estendidas a outros autores, como Afrânio Coutinho, Antonio Candido e Massaud Moisés. Em "A cidade e a letra", Portella parte da mesma constatação que vinha intrigando a crítica literária do período: "a constância com que vem aparecendo, ultimamente, os chamados livros de crônicas" (PORTELLA, 1959, p.103). Contudo, Portella vê com bons olhos o fenômeno, pois seriam "livros de crônicas que transcendem a sua condição puramente jornalística para se constituir em obra de arte literária", contribuindo, assim, "para fazer da crônica um gênero literário específico, autônomo" (PORTELLA, 1959, p.103). Os autores que são por ele abordados em seu artigo correspondem aos principais representantes do gênero no período entre 1956 e 1958, como Rubem Braga, Drummond, Bandeira, dentre outros. A questão para Portella é como lidar com a transcendência na crônica, visto que ela prima pela ambiguidade, inclinando-se na direção dos mais variados gêneros (conto, ensaio, poema em prosa), às vezes sendo praticamente absorvida por aquele do qual se aproxima. Se, de um lado, Portella destaca a plasticidade do gênero, de outro lembra o seu limite, ou seja, o caráter efêmero do veículo de comunicação, o jornal, ao qual a crônica deve a sua origem. É nesse momento que a ambiguidade se torna ponto favorável à sua conversão literária, na medida em que lhe 
permite transcender, o que pode ser facilitado pelas características do gênero do qual se avizinha: "o enriquecimento poético da crônica é uma maneira das mais eficazes de fazê-la transcender, de fugir ao seu destino de notícia para construir o seu destino de obra de arte literária" (PORTELLA, 1959, p.106). Nesse sentido, segundo Portella, a "publicação frequente de livros de crônica" (PORTELLA, 1959, p.109) facilitaria o reconhecimento das realizações do gênero que, a despeito das condições originais de produção efêmera, atreladas às demandas do dia a dia, teriam atingido o "poder de transcendência" literária.

Aqui os extremos se tocam: contra ou a favor da crônica, a perspectiva é a mesma, baseada na literatura como transcendência e no livro como único instrumento capaz de assegurá-la.

Tentarei problematizar a questão, principiando pelo que diz respeito ao livro, para depois discutir aí o possível efeito de transcendência.

Parto do seguinte ponto: se o livro torna perceptível a transcendência de certos exemplares da crônica, como sugere Portella, em que medida esse fenômeno seria específico do gênero, já que se pode esperar de um romance, ou de um poema, que ele suscite no leitor a impressão de ter ultrapassado o seu tempo, produzindo um eterno efeito de contemporaneidade? Claro que se pode argumentar que, por conta mesmo de sua procedência jornalística, nenhum outro gênero estaria tão vinculado ao presente mais imediato do que a crônica e, por isso mesmo, para se perpetuar, ela dependeria mais das condições proporcionadas pela materialidade do livro. A favor do argumento, bastaria lembrar a obra de Rubem Braga, autor que se celebrizou apenas como cronista. Como exemplo, menciono o seu livro Ai de ti, Copacabana que, em 2010, vinte anos após a morte do autor, alcançava a vigésima oitava edição - a primeira é de 1960. Entretanto, não seria difícil citar livros de gêneros consagradamente literários que não chegaram à metade dessa cifra, e isso quando conseguiram superar o desafio da primeira edição. Assim, o pesquisador que se interessasse pela obra de João Manuel Pereira da Silva, escritor que se notabilizou em meados do século XIX pela expressiva quantidade de livros publicados nos mais diversos gêneros, inclusive no romance, e cujo nome até hoje aparece mencionado em quase todos os manuais de historiografia literária, poderia se surpreender ao constatar que apenas um livro desse vasto acervo foi reeditado no século XX, no caso, Memórias do meu tempo, por uma editora cuja distribuição é restrita, a do Senado Federal, e que poucos títulos do autor podem ainda ser encontrados em sebos ou em bibliotecas, públicas ou não.

Ora, se escrever romances e poemas para serem impressos originariamente em livros não garante a sobrevivência de uma obra, escrever sob as condições específicas de difusão periódica não a condena ao desaparecimento. Até porque, romances e poemas foram, muitas vezes, escritos para figurarem em jornais e revistas, extinguindo-se com as folhas que lhe serviram de suporte; no entanto, muitos também desapareceram nas páginas do livro, hoje acessíveis apenas em bibliotecas especializadas, logo sujeitos às mesmas exigências de pesquisa enfrentadas por aqueles que se dedicam à investigação de material jornalístico. Se $O$ guarani, de José de Alencar, escrito e publicado diariamente nos primeiros meses de 1857 nas páginas do Diário do Rio de Janeiro, torna-se um clássico da literatura brasileira frequentemente reeditado, Jerônimo Corte Real, romance do já aqui citado Pereira da Silva, também divulgado de modo seriado, só que no Jornal do Commércio em 1840, não vai além da terceira edição de 1865 - vale lembrar que ambos os autores aparecem no catálogo da mais importante editora da época, a Garnier.

Assim, o efeito de transcendência de um texto não depende da materialidade do livro. Essa ideia corrente, aqui apresentada sobretudo pelo artigo de Temístocles Linhares, esbarra em pelo menos dois problemas: o primeiro diz respeito à própria natureza do registro escrito que, a despeito do suporte - da pedra à tela, passando pelo livro e o jornal -, permite ao texto romper o limite de seu contexto original de enunciação. Ou seja, uma vez inscrito, o 
texto pode ser recuperado nos mais variados contextos de recepção; o segundo problema, diretamente derivado do anterior, encerra em si uma contradição, pois, historicamente, o livro, ao invés de assegurar a transcendência do texto, tendeu a promover o seu esquecimento. À medida que o livro se torna, a partir do século XV, o principal objeto consagrado ao registro e estocagem de textos escritos e, ao mesmo tempo, o veículo mais utilizado para a sua difusão, a memória perde gradativamente o lugar privilegiado no intercâmbio comunicativo, perda que, obviamente, não se deve apenas à ascensão do livro, mas que é também fruto de um longo processo cujo principal impulso foi o expressivo desenvolvimento da escrita, sobretudo a partir da invenção do alfabeto grego, atrelado ao surgimento gradativo de todo um conjunto de dispositivos materiais de apresentação textual (separação de palavras, pontuação, divisão em parágrafo, layout da página, etc.). Desse modo, uma vez registrado e devidamente encadernado, o texto acaba muitas vezes sobrevivendo apenas como relíquia histórica, encerrado em bibliotecas, sem nunca ter existido na memória afetiva de leitores coetâneos de sua primeira aparição pública e ainda correndo o risco de não ser recuperado por futuros leitores. Desse modo, se o livro pode garantir a sobrevivência material do texto - por sinal, como o faria qualquer outro suporte de inscrição -, não assegura, contudo, que ele será apropriado por atos contínuos de leitura, isto é, o efeito de transcendência só se manifesta a partir do interesse despertado pelo texto e que se renova ao longo dos tempos, motivando sucessivas reedições, sem as quais ele não estaria em melhor situação do que se publicado na imprensa periódica ou em uma lápide. Nesse sentido, o fenômeno pode ser estendido a Rubem Braga ou a qualquer outro escritor, cronista ou não.

Se a noção de transcendência não se sustenta no livro, ela é ainda mais prejudicial em relação ao entendimento do próprio gênero, pois a transcendência, na verdade, descaracteriza-o, já que desfaz a ambiguidade que lhe constitui. Assim, se aceitasse a reflexão de Portella como princípio, diria que a crônica, ao buscar na interface com outros gêneros, principalmente os poéticos, um modo de superar as contingências de sua publicação, acabaria sendo absorvida de tal modo que a ambiguidade despareceria em favor dos gêneros com os quais dialoga. Para Portella, a autonomia da crônica corresponde ao afastamento do que há nela de jornalístico. É como se a crônica para se tornar literatura tivesse de deixar de ser crônica.

Para finalizar, gostaria de retornar a um texto clássico de Machado de Assis sobre o tema. Trata-se da série "Aquarelas", publicada em $O$ Espelho, em 1859. Assinalo o item "Folhetinista", no qual o autor de Dom Casmurro ressalta a procedência jornalística da crônica: "o folhetim nasceu do jornal, o folhetinista por consequência do jornalista. Esta íntima afinidade é que desenha as saliências fisionômicas na moderna criação" (ASSIS, 1859, p.1). É dessa familiaridade que emerge a ambiguidade característica do escritor do gênero: "o folhetinista é a fusão admirável do útil e do fútil, o parto curioso e singular do sério, consorciado com o frívolo" (ASSIS, 1859, p.1). Segue, então, o resultado da síntese:

Efeito estranho é este assim produzido pela afinidade assinalada entre o jornalista e o folhetinista. Daquele cai sobre este a luz séria e vigorosa, a reflexão calma, a observação profunda. Pelo que toca ao devaneio, à leviandade, está tudo encarnado no folhetinista mesmo: é capital próprio. (ASSIS, 1859, p.1)

Não é difícil retirar dessas passagens certa interpretação que entende a ambiguidade como articulação entre os polos jornalístico e literário: o par "útil/sério" estaria para o primeiro polo assim como o "fútil/frívolo" para o segundo. Entretanto, o texto machadiano estabelece uma articulação não entre o jornalístico e o literário, mas, sim, entre o jornalístico e o folhetinesco, esse compreendido como uma nova modalidade discursiva que requer novas práticas combinadas com as já existentes no interior do próprio jornal, de acordo com o seu estágio de desenvolvimento em meados do século XIX. Assim, Machado ressalta a 
ambiguidade sem, contudo, remetê-la ao literário, o que nos permite desconsiderar qualquer possibilidade de transcendência, pelo menos no sentido de um programa previamente estabelecido para aqueles que se dedicam à escrita do gênero - se a transcendência vai se manifestar como efeito de leitura de futuras recepções, isso já é outro problema que pode ser, em alguns casos, associado à determinada concepção tradicional de literatura, inclusive defendida por críticos com a boa vontade de salvar a crônica do ostracismo.

Como a entendo, a crônica deve ser pensada no interior da esfera jornalística, o que não significa dizer que ela não pode ser considerada em outros suportes - livro, rádio, televisão ou mesmo os mais recentes meios digitais de difusão - como modo de se estabelecer o seu percurso enquanto gênero. Sob esse prisma, a escrita de sua história supõe reinseri-la em contexto original de produção, circulação e recepção assumindo uma perspectiva sem a qual a crônica tenderia a permanecer apenas como apêndice dos manuais de história literária.

\section{REFERÊNCIAS}

ASSIS, Machado de. Aquarelas. O Espelho: Revista semanal de literatura, modas, indústria e artes. Rio de Janeiro, p.1, 30 out. 1859.

LIMA, Alceu de Amoroso. Estudos: quinta série. Rio de Janeiro: Civilização Brasileira, 1933.

BRASIL, Francisco de Almeida Assis. A crônica é o limite. Jornal do Brasil, Rio de Janeiro, 7 ago. 1963. Caderno B, p. 1.

CAVAlHEIRO, Edgar. A semana e os livros. O Estado de S. Paulo, São Paulo, 16 nov. 1957. Suplemento Literário, p. 4.

LEMOS, Tite de. Os olhos dourados do ódio. Cadernos Brasileiros. Rio de Janeiro, n. 4, jul./ago., 1963.

LINHARES, Temístocles. Cronistas escritores. O Estado de S. Paulo, São Paulo, 20 out. 1957. Suplemento Literário, p. 4.

Situação da crônica. O Estado de S. Paulo, São Paulo, 16 fev. 1963. Suplemento Literário, p. 4.

NASCIMENTO, Esdras. Cony rebelado: Crônica é negócio. Tribuna da Imprensa. Rio de Janeiro, p. 9, 24 jul. 1963. $\overline{\text { jul. } 1963 .}$

Cony com razão: crônica é negócio. Tribuna da Imprensa. Rio de Janeiro, p. 1, 31

OLIVEIRA, José Carlos. Declaração de honestidade. Jornal do Brasil, 26 jul. 1963. Caderno B, p. 1 .

PORTELLA, Eduardo. A cidade e a letra. In: Dimensões I: crítica literária. Rio de Janeiro: Agir, 1959. 
Recebido em: 09 de julho de 2015.

Aceito em: 29 de julho de 2015. 